\title{
Understanding through modeling: the explanatory power of inadequate representation
}

\author{
Markus Eronen ${ }^{1} \cdot$ Raphael van Riel $^{2}$
}

Published online: 20 November 2015

(C) Springer Science+Business Media Dordrecht 2015

The claim that models are representationally inadequate, as the title of this special issue tentatively suggests, is provocative. Isn't it the case that, by their very nature, models aim at idealization, approximation, and simplification? These features are often seen as merits rather than defects of models. Pragmatists and instrumentalists have argued extensively that this kind of "inadequacy" does not matter, as long as models serve their descriptive or predictive purposes. However, models also seem to play a vital role in understanding and explaining reality and in giving us descriptions of what there is; prima facie, their function does not reduce to merely enabling us to somehow get along. Given their representational "deficiencies", it is not at all clear to which extent and how models can help us understand the world, or how they can possibly exhibit something like explanatory power.

In recent years, various proposals concerning the metaphysics of models as well as their representational nature have been advanced (Frigg 2010; Godfrey-Smith 2006; Weisberg 2013; Giere 2004; Alexandrova 2008; Toon 2012; Bokulich 2009; Strevens 2008; García-Carpintero 2010). However, these accounts have not provided a satisfactory or broadly accepted answer to the epistemic value of representationally inadequate models. The pragmatic value of at least some scientific models is beyond suspicion, but do they also enable us to better understand and explain their target systems? More specifically, it is not clear what are the features in virtue of which some (inadequate) models provide understanding, while others do not.

\footnotetext{
Markus Eronen

markus.eronen@hiw.kuleuven.be

Raphael van Riel

raphael.vanriel@uni-due.de

1 Institute of Philosophy, KU Leuven, Leuven, Belgium

2 Institut für Philosophie, Universität Duisburg-Essen, Essen, Germany
} 
At the same time, many contemporary epistemologists have shifted attention from concepts such as knowledge and justification to the concept of understanding (Kvanvig 2003; Elgin 2009; Grimm 2006). What plays a crucial role in these debates is the alleged factivity of understanding, i.e., the intuitively plausible idea that understanding presupposes the truth of what grounds understanding: for example, scientific theories such as the general theory of relativity lead to understanding only if they are true theories. In this context, "understanding" based on scientific models poses an interesting case. On the one hand, understanding provided by scientific models seems to be genuine understanding, but on the other hand, it often seems to be non-factive, as the models involved are known to be literally false.

This special issue brings together these debates in philosophy of science and epistemology, aiming at a comprehensive view of different aspects of understanding and its relation to modeling. The roots of this special issue are in two workshops organized by the editors ('Explanatory power', May 2012, Ruhr University Bochum and 'Explanatory Power II: Understanding through modeling', April 2013, Ruhr University Bochum). Selected speakers (and several other experts on the topic) were invited to submit their papers to this special issue, and the submitted papers went through a strict peer review process. This resulted in ten papers that are now published in this volume.

In the first contribution, 'Scientific understanding: truth or dare?' Henk de Regt provides an illuminating introduction to the debate on the alleged factivity of understanding. His main concern with the factive view is that it seems to imply that many scientific models and past scientific theories (such as Newton's theory of gravitation) cannot provide understanding. The solution de Regt proposes is to sever the link between truth and understanding and to connect understanding to the "intelligibility" of theories. Christoph Kelp ('Understanding phenomena'), in contrast, defends a factive approach to understanding. He points out various problems in recent accounts of understanding by authors such as de Regt, Wilkenfeld, and Khalifa, and then presents a novel knowledge-based account that arguably avoids these problems. His proposal is that maximal understanding of a phenomenon amounts to fully comprehensive knowledge of it.

Jaakko Kuorikoski and Petri Ylikoski approach understanding from the perspective of model-based reasoning in science ('External representations and scientific understanding'). They propose an inferential account of understanding, according to which models provide understanding insofar as they allow scientists to make correct what-if inferences about objects or systems of interest. Importantly, this does not require the models themselves to be literally true. Similarly to Adam Toon (see below), the authors also argue that modeling can be seen as a form of extended cognition. Raphael van Riel ('The content of model-based information') provides a complementary viewpoint by analyzing understanding with the tools of philosophy of language. He first points out fundamental problems in the popular view that (false) models provide understanding by providing knowledge about possibilities, and then proposes an alternative: Models lead to understanding when they provide knowledge about how an actual object behaves (in a context) according to the model. In this way, models can provide understanding even when they are literally false: In the right context, some explanations or predictions that are true according to the model can be true simpliciter. 
The idea that understanding is a form of extended cognition forms the main topic of Adam Toon's paper ('Where is the understanding?'). Building on recent work in the philosophy of mind and cognition, Toon suggests that states of understanding are states that involve brain, body, and world, and argues that the grasping of an explanation or seeing a connection that is supposed to account for understanding should be construed in a literal, rather than a metaphorical sense: it involves interaction with external objects.

The paper 'On the role of explanatory and systematic power in scientific reasoning" by Peter Brössel concerns the issue of explanatory power and the much-disputed strategy of inference to the best explanation (IBE). Brössel defends IBE and proposes an additional inference schema, "inference to the best systematization" (IBS), arguing that it is truth-conducive and a good criterion for theory choice. Brössel also goes through van Fraassen's classic criticism of IBE, and shows that it does not undermine the IBS schema.

Cameron Buckner ('Functional kinds: a skeptical look') tackles the issue of modeling and explanatory power in the context of functional kinds, arguing against Dan Weiskopf's account of non-localizable functional kinds. According to Buckner, the strategy of grounding functional kinds in modeling practices (instead of laws or mechanisms) at best leads to kinds with limited counterfactual explanatory power. Thus, it is more plausible to interpret such "functional" kinds as mechanism sketches. In contrast, Elizabeth Irvine introduces and defends a form of non-causal and non-mechanistic explanation in cognitive science and biology ('Models, robustness, and non-causal explanation: a foray into cognitive science and biology'). She focuses on phenomena that are robust in the sense that they are optimal states that remain invariant across a broad range of interventions ("O-robustness"). Due to their immunity to interventions, such phenomena cannot be explained causally-mechanistically; they are rather explained by appealing to the structural features of the model. In 'Robustness and reality', Markus Eronen also discusses robustness, but focuses on the more general idea of robustness as multiple means of accessing or measuring a phenomena. Building on the work of William Wimsatt, he argues that this kind of robustness can potentially provide justification for ontological commitments. He also considers some of the ways in which robustness can play a useful role in the debate on scientific realism.

The final paper of this volume ('An assessment of the foundational assumptions in high-resolution climate projections: the case of UKCP09') illustrates how the issue of modeling and understanding also has relevance for scientific practice and even political decision making. Roman Frigg, Leonard Smith, and David Stainforth discuss the United Kingdom Climate Impacts Programme (UKCP09) that is intended to give high-resolution climate projections for the coming decades. The authors show that the UKCP09 methodology suffers from systematic errors and problematic assumptions, which casts significant doubt on the reliability of the projections.

We believe that this special issue clarifies and illuminates the relationship between imperfect models and understanding and explanatory power, and presents state-of-theart contributions to the topic. The fact that the authors come from various backgrounds and career stages indicates how important and current the issue is in many fields of philosophy. We hope that the papers in this issue also motivate others to carry out further research on this topic, as the debate is far from over. 
Acknowledgments We would like to thank Albert Newen (Ruhr-University Bochum) for his support, without which none of the workshops would have taken place. We also would like to thank the Volkswagen Foundation and the Research Foundation Flanders (FWO) for their generous support of Raphael van Riel's project "A Study in Explanatory Power" and Markus Eronen's postdoctoral fellowship respectively. We would like to express our gratitude to all the referees who did such a rigorous job in a timely manner, and to Otávio Bueno for all his support and assistance as the editor-in-chief taking care of this issue.

\section{References}

Alexandrova, A. (2008). Making models count. Philosophy of Science, 75, 383-404.

Bokulich, A. (2009). How scientific models can explain. Synthese, 180(1), 33-45.

Elgin, C. (2009). Is understanding factive? In A. Haddock, A. Millar, \& D. H. Pritchard (Eds.), Epistemic value (pp. 322-330). Oxford: Oxford University Press.

Frigg, R. (2010). Models and fiction. Synthese, 172(2), 251-268.

García-Carpintero, M. (2010). Fictional entities, theoretical models and figurative truth. In R. Frigg \& M. C. Hunter (Eds.), Beyond mimesis and convention: Representation in art and science (pp. 139-168). Berlin: Springer.

Giere, R. (2004). How models are used to represent reality. Philosophy of Science, 71, 742-752.

Godfrey-Smith, P. (2006). The strategy of model-based science. Biology and Philosophy, 21, 725-740.

Grimm, S. (2006). Is understanding a species of knowledge? British Journal for the Philosophy of Science, $57,515-535$.

Kvanvig, J. (2003). The value of knowledge and the pursuit of understanding. Cambridge: Cambridge University Press.

Strevens, M. (2008). Depth: An account of scientific explanation. Cambridge, MA: Harvard University Press.

Toon, A. (2012). Models as make-believe: Imagination, fiction and scientific representation. London: Palgrave Macmillan.

Weisberg, M. (2013). Simulation and similarity. Using models to understand the world. Oxford: Oxford University Press. 